\title{
FILOSOFAR ENQUANTO CUIDADO DE SI MESMO: UM EXERCÍCIO ESPIRITUAL ÉTICO-POLÍTICO
}

\author{
Luiz Rohden ${ }^{1}$ \\ Leonardo Marques Kussler ${ }^{2}$

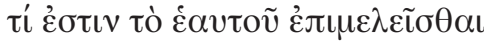 \\ O que é cuidar de si mesmo? (PLATÃO, Alcibiades I, 127 e)
}

\begin{abstract}
Resumo: $\mathrm{O}$ texto que tecemos e aqui apresentamos constitui, em síntese, uma resposta à provocante pergunta de Platáo o que é cuidar de si? As respostas que oferecemos consistem em traços da nossa proposta de compreensão de filosofia que se efetiva enquanto um exercício espiritual, que, por sua vez, sustenta a hipótese do filosofar enquanto um modo de viver. Para tanto, da filosofia grega, explicitaremos o exercício do cultivo de si corporificado em Sócrates e, por parte da filosofia oriental, analisaremos o personagem Musashi. Ambos personificam a opção por um estilo de vida filosófica e modo de ser - o primeiro, pelas veredas do diálogo, o segundo, pela vivência - e assinalam a necessidade da evolução espiritual da alma, mediante vida contemplativa. Consequentemente, além de explorar a enorme proximidade entre uma linha filosófica grega e a tradição oriental, fundamentaremos o solo comum do pensamento enquanto exercício ético.
\end{abstract}

Palavras-chave: Platão. Cuidado de si. Exercício espiritual. Exercício ético-político. Filosofia como modo de vida.

\section{INTRODUÇÃo}

Platão, ao solicitar a Alcibíades que explicasse o significado da expressão "cuidado de si mesmo" (Alcibiades, 127 e), lançou uma questão filosófica que pede nossa resposta ainda hoje. Essa é a provocação filosófica que nos ocupa, hoje, aqui, e que nos levou a explicitar e justificar o processo filosófico enquanto cuidado de si mesmo, que se efetiva em forma de exercício espiritual, o qual visa ao cultivo da virtude pessoal que implica uma postura política. Tratase de tematizar e desenvolver, pois, uma perspectiva filosófica não hegemônica, mas que julgamos pertinente, apropriada, salutar e cujas raízes se estendem ao mundo oriental. Isso justifica por que traçaremos um paralelo reflexivo-

\footnotetext{
${ }^{1}$ Professor Titular I e Coordenador do PPG UNISINOS. E-mail: rohden@unisinos.br Apoio do CNPq - Edital Ciências Humanas, Sociais e Sociais Aplicadas/ Projeto 22/2014

2 Doutorando em Filosofia pela UNISINOS, Bolsista PROSUP/CAPES. E-mail: leonardo.kussler@ gmail.com

http://dx.doi.org/10.1590/S0101-31732017000300006
} 
argumentativo entre nossa hipótese de trabalho - filosofar, um cuidado de si mesmo, mediante exercício espiritual enquanto uma prática ético-política - e uma face da tradição oriental ${ }^{3}$.

Assim como o Ser se diz de muitas maneiras, de acordo com Aristóteles (Met., IV, 1103a), a filosofia se realiza por distintos caminhos. A efetivação da felicidade, por meio de exercício compreensivo do mundo e de si mesmo, percorre caminhos distintos que podem se tocar e se distanciar, como é o caso da filosofia e da tradição literária, no caso, oriental. Se, por um lado, a filosofia se caracteriza como o exercício de abstração da realidade, elaborando um discurso com pretensão de validade universal, ela se realiza também pela marcha inversa, isto é, do conceito à palavra, ou seja, trilhando o caminho da contemplação das ideias à libertação dos prisioneiros na caverna (GADAMER, 2000b). Escolhemos Sócrates como a corporificação desse significado de filosofia, por parte da tradição ocidental, e, da tradição filosófico-literária oriental, julgamos que o personagem Musashi, da obra de Eiji Yoshikawa, representa nossa hipótese de investigação. Musashi, em nossa opinião, corporifica o exercício espiritual filosófico, passando de um modo de vida inicial bruto, violento, para uma prática de vida final harmônica e una.

O fato é que ambas as tradiçóes se justificam e se constituem como práticas tecidas pelos fios da linguagem, de modo que o exercício de sua compreensão lhes é inerente. Os textos - no caso, o de Platão e seu personagem Sócrates e o de Yoshikawa e seu personagem Musashi são tecidos por significados compreensíveis no ato da leitura. Ambas as produçôes textuais corporificam, "presentificam significados" cuja "[...] chave para entender a corporificação [...] é a interpretação" (DANTO, 2010, p. 18), cujo escopo é instaurar sentidos para nossas vidas. Os textos carregam transfiguraçôes de lugares-comuns que são completados com o exercício de leitura (ROHDEN, 2015a).

Ora, levando em conta que "[...] um texto não é uma entidade fechada sobre si mesma”, mas "[...] é projeção de um novo universo distinto daquele no qual vivemos" (RICOEUR, 2006, p. 15), a leitura dos textos acaba por afetar o modo de viver de quem os lê. Dessa forma, enquanto exercício de compreensão do mundo, ambos dizem respeito, em última instância, à autocompreensão e à orientação de vida do intérprete e, por isso mesmo, constituem uma prática ética. Assim, tanto os textos escritos, com seus

${ }^{3}$ Ver, ainda, sobre a reflexão entre Ocidente e Oriente, Rohden e Kussler (2016, p. 261-282). 
personagens arquetípicos, como a hermenêutica que fazemos deles - como é nosso propósito apresentar aqui —, atestam o pressuposto e a implicação ética presentes na tradição filosófica e no pensamento oriental.

Teceremos nossa reflexão com indicações da filosofia enquanto modo de viver socrático-platônico que Hadot e Foucault sustentam. Especificamente, mostraremos que a filosofia pode ser compreendida como uma escolha por um modo de vida que se efetiva mediante exercício espiritual e indicaremos a proximidade com a trajetória do guerreiro. Este, regido por um código de disposição e conduta, na busca pela harmonização de sua alma, assemelha-se ao flósofo, que também deveria conduzir sua existência de forma virtuosa.

Para tanto, dividiremos o artigo em três seções principais: a) a filosofia enquanto efetivação do cuidado de si corporificado no modo filosófico de viver de Sócrates e no modo de vida de Musashi; b) o filosofar enquanto um exercício espiritual que afeta e transforma a modo de viver — visível tanto em Sócrates quanto em Musashi - com finalidade ética; c) o cuidado de si mesmo e o exercício espiritual enquanto experiência prático-política, momento em que explicitaremos e justificaremos que o processo das práticas de si tem um fim que transcende o nível particular e pessoal, pois implica a prática política personificada pelos personagens Sócrates e Musashi.

\section{O FILOSOFAR ENQUANTO CUIDADO DE SI MESMO}

Após a publicação da obra hadotiana que defendera a tese de a filosofia ser uma união entre sua própria teoria (o discurso) e sua prática (o modo de vida filosófico), Foucault publica uma série de estudos sobre o controle do corpo e o uso dos prazeres, adotando uma abordagem filosófica e histórica quanto à noção de domínio de si e, posteriormente, cuidado de si. Provavelmente, o autor mais expressivo a respeito da compreensão de filosofia como uma prática de si é Foucault, que reinterpreta a tríade délfica - conhecimento de si, cuidado de si, nada em demasia —, reorientando o grau de importância e a negligência histórica

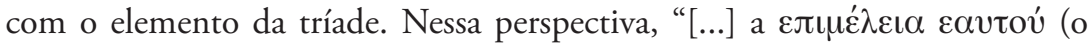
cuidado de si) é realmente o quadro, o solo, o fundamento a partir do qual se justifica o imperativo do 'conhece-te a ti mesmo'." (FOUCAULT, 2006, p. 11). Ora, se o cuidado de si é o fundamento justificativo do conhecimento de si, quer dizer que não só o precede como é condição para que ele seja instituído.

Entretanto, seguindo a tese foucaultiana, parece que, historicamente, 


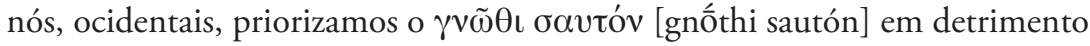

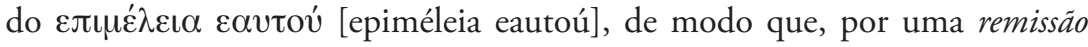
da filosofia à dimensão teológica, suas práticas que antes condiziam com a compreensão do que era filosofia ou ser filósofo acabaram por tornarem-se

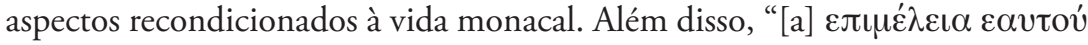
[epiméleia eautoú], a cura sui é uma injunção que se encontra em muitas doutrinas filosóficas" (FOUCAULT, 2005, p. 50), não apenas na tradição platônica e neoplatônica, pois, muito provavelmente, grande parte das práticas originam-se do pitagorismo, que, por sua vez, deriva, em parte, do orfismo egípcio - e, obviamente, de técnicas milenares orientais que a antecedem.

Sócrates, na Apologia (29 d-e), adverte seus interlocutores a cuidarem de si mesmos pelas seguintes palavras:

Excelentíssimo homem, tu, que és um cidadão de Atenas, a maior das cidades e a mais famosa pela sabedoria e pelo poder, não estás envergonhado em cuidares da aquisição de riqueza e reputaçáo, quando não cuidas nem pensas sobre a sabedoria, a verdade e o aperfeiçoamento da

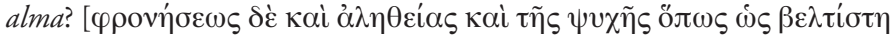

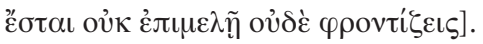

Cuidar de si mesmo, pois, significa dar atenção ao que é, de fato, essencial para a realização da felicidade cultivando sua alma. Em sua defesa, Sócrates (Apologia, 30 a-b) lembra que sua missão filosófica consistiu, desde sempre, em alertar e persuadir os atenienses a não cuidarem

[...] de seus corpos ou de sua propriedade mais do que do aperfeiçoamento de suas almas, ou mesmo muito; e digo-lhes que a virtude não provém do dinheiro, mas da virtude provém o dinheiro e todas as outras coisas boas ao

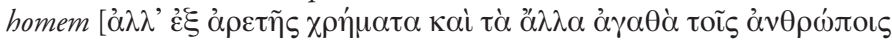

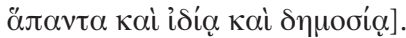

No Alcibiades I, a preocupação principal é cuidar e ater-se ao cuidado da alma, para obter soberania sobre si mesmo e, assim, poder ser soberano dos outros. A preocupação gira em torno da preparação psicagógica de Alcibíades em relação à sua ânsia por tornar-se um representante político da cidade, mas sem a formação necessária para tal, baseando-se apenas no direito adquirido por sua linhagem nobre. A conclusão do diálogo é: "Com efeito, agora sabemos que é preciso ocuparmo-nos com nós mesmos. E a questão está em saber o 


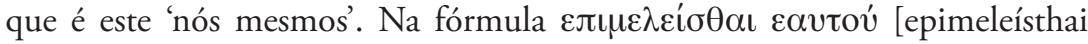
eautoú], o que é o $\varepsilon \alpha v \tau o u ́$ [eautoú]?” (FOUCAULT, 2006, p. 66). Trata-se de uma investigação pessoal com vistas à compreensão, ao cuidado e à iluminação de si mesmo. Nesse sentido, a filosofia compreende-se como discurso - como atesta a tese de Hadot —, e como uma prática que transforma o sujeito, isto é, "Filosofia [entendida] como $\theta \varepsilon \rho \alpha \pi \varepsilon v ́ \varepsilon ı v ~ \varepsilon \alpha v \tau o u ́$ [therapeúein eautoú]." (FOUCAULT, 2006, p. 120).

Após a difusão da filosofia grega, a partir dos autores basilares da Grécia Antiga e seu encaminhamento às tradiçóes pós-socráticas - cinismo, epicurismo, estoicismo e ceticismo - , "[...] a filosofia vinha, cada vez mais, buscando sua definição, seu centro de gravidade, fixando seu objetivo em torno de alguma coisa que se chamava $\tau \dot{\chi} \chi v \eta ~ \tau o \tilde{~ \beta i ́ o v ~[t e ́ c h n e ̄ ~ t o u ̂ ~ b i ́ o u], ~ i s t o ~ e ́, ~ a ~}$ arte, o procedimento refletido da existência, a técnica de vida." (FOUCAULT, 2006, p. 218-219). Explorou-se, então, a perspectiva da filosofia como uma espécie de arte de bem viver, de sorte que a vida a passou a ser tomada como uma obra de arte, a qual deveria ser burilada diariamente. Isso ficou atestado na afirmação de Sócrates (Apologia, 38 a) segundo a qual "[...] a vida sem

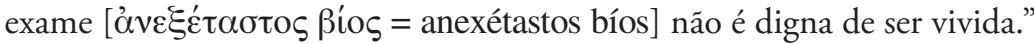

A filosofia compreendida como arte de bem viver concebe o cuidado de si que implica uma transformação do modo de vida levado até então, uma espécie de reflexão sobre as próprias atitudes e uma revaloração da própria existência. Portanto, "[...] o objetivo comum dessas práticas de si, através das diferenças que elas apresentavam, pode ser caracterizado pelo princípio do bem

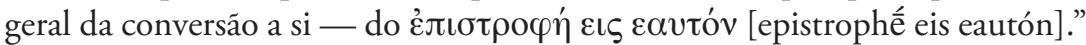
(FOUCAULT, 2005, p. 69). Nesse sentido, a aprendizagem e a orientação da alma são importantes, na medida em que o mestre aplica seus ensinamentos através do exemplo de seu próprio modo de vida, além de dialogar com o discípulo, aconselhando-o e exortando-o quanto ao cuidado de si mesmo e à conversão do olhar e da escuta de si mesmo.

Musashi é um romance japonês, de Eiji Yoshikawa, que narra a caminhada e a ascendência espiritual de Shinmen Takezō — posteriormente, renomeado como Miyamoto Musashi — , um personagem real, que viveu no Japão de 1584 a 1645. Musashi representa a imagem de samurai ideal, que harmoniza seu modo de ser, sua própria existência, de acordo com o discurso filosófico - da filosofia zen-budista e do bushido, o caminho do guerreiro.

O monge Takuan é o responsável por colocar Takezō em busca 
do caminho da espada, de uma concepção filosófica que o faz converterse a si mesmo, exercitar-se em um tipo de meditaçáo e aprofundar-se no autoconhecimento, no cultivo da própria alma, no domínio de si mesmo e no controle das paixôes. Takuan inspira Takezō a experienciar a morte, pois, ao ser solto do cedro centenário, no qual estava pendurado de ponta-cabeça, ele renasce ao cair no chão estável, que o ampara com sua imobilidade e contenção. Em peregrinação com o monge, o personagem é conduzido a uma experiência de clausura, forçando-o à iniciaçáo do letramento e dos fundamentos do zenbudismo, no capítulo intitulado a cela de luz, que representa a iluminaçáo pessoal e o novo batismo, sob o nome de Miyamoto Musashi (YOSHIKAWA, 2003a, p. 141 et seq).

Preso na torre, Musashi passa da bestialidade à serenidade, inclusive com novos dotes artísticos de desenhos e um novo nível de apreciação estética. Musashi é, agora, um estrategista, alguém que se coloca como um ser cuja vida é muito valiosa; há uma conversão de um niilista a um vitalista, que sabe a hora de recuar e desistir de uma batalha ou ponderar sobre o fato de ter que tomar a vida de outrem. Musashi já se mostra alguém que procura outros guerreiros com o intuito de se pôr a teste, de saber o valor da própria técnica, o grau de sua própria evoluçáo, pensando em seu inimigo exterior — aqueles com quem entrava em embate - e na causa ocasionada por seu inimigo interior — suas paixôes e a luta para a orientação da alma. Nikkan, o velho monge de um dos templos descritos na história, pondera sobre sua caminhada: "Você é forte demais. Aprenda a conter um pouco a sua força." (YOSHIKAWA, 2003a, p. 248). Musashi não enxerga mais as coisas como antes e "[...] tinha plena consciência de que a transformação ocorrera não apenas em relação ao modo como encarava a esgrima, mas também quanto à sua visão da sociedade em geral, e dos homens em particular." (YOSHIKAWA, 2003a, p. 257).

A perspectiva do cuidado de si como modo em que a aprendizagem filosófica é constituída leva em consideração não apenas a criticidade, ao ouvir dado discurso filosófico, mas, antes, de captá-lo como passível de avaliação, acolhimento e pretexto para um olhar a si mesmo, um exame de consciência que considere o equipamento existencial adquirido até então e a possibilidade de melhoria.

Sócrates é um ideal de ser filósofo, o qual representa alguém que arrisca, com bravura, sua própria vida em nome do direito/dever de dizer a verdade, que é uma das funçóes esperadas por quem exercita o cuidado de si. Os primeiros diálogos platônicos, comumente chamados de socráticos, exploram 
o aspecto teórico e prático, isto é, a dimensão teorética, contemplativa, e sua aplicação em forma de exercício espiritual, de cuidado de si, de modo de vida. O filósofo, pois, é alguém que se prepara, não apenas para si mesmo, em um exercício solipsista, porém, para a vida em sociedade, para o outro, como alguém que não somente produz discursos e emite juízos, mas que toma atitude com relação aos problemas.

De certa forma, Takuan está para Musashi assim como Sócrates estava para seus discípulos, pois a função é similar, isto é, de parresiasta e de pregador da filosofia em sua missão de alerta do autoconhecimento e da compreensão do cuidado de si. Tanto é verdade que, assim como Platão assume o lugar de Sócrates, em sua missão de instruir os mais jovens e incluí-los em uma vida em comunidade contemplativa, Musashi faz o mesmo com um jovem que encontra em seu percurso, Jōtarō. Em um diálogo específico, Musashi afirma: "Preste atenção, Jōtarō: a aprendizagem de um guerreiro não deve limitar-se a duelos. [...]. A verdadeira aprendizagem consiste em polir o espirito, mais que as técnicas marciais. [...] observando com os olhos do espírito." (YOSHIKAWA, 2003b, p. 285).

Enfim, retomando o trecho da Apologia supracitado, um homem não cuida de si mesmo quando cuida das riquezas que possui, da aquisição de poder e de honrarias. O cuidado de si mesmo, essa arte de tornar-se melhor, mais sensato, mais livre, exige autoconhecimento, como lemos no Alcibiades $I$ (129 a), que, "[...] se tivermos tal conhecimento, somos capazes de saber

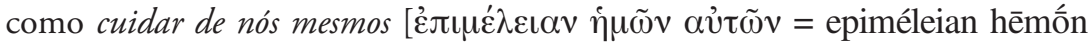
autốn]." Vimos que o cuidado de si mesmo — seja nas pegadas de Sócrates, seja na trilha de Musashi — pauta a construção teórica e a conduta próprias de uma concepção de literatura filosófica. O fato é que, "[...] desde a origem da filosofia, e, talvez, de fato, até agora, apesar de tudo, o Ocidente sempre aceitou que a filosofia não poderia ser separada de uma existência filosófica, que a prática da filosofia sempre deveria ser mais ou menos um tipo de exercício de vida." (FOUCAULT, 2011, p. 235).

Isso pode ser resumido nas palavras de Sócrates, na Apologia (41 e), ao recordar que sua missão consistiu em tentar persuadir os atenienses a cuidarem menos do que era seu, com vistas a ser melhor e mais sensato, ou seja, mais feliz, mais justo. Nesse horizonte, seu pedido para que castiguem seus filhos, caso se [pre]ocupem mais com coisas materiais do que com a virtude continua fazendo sentido. O filosofar enquanto cuidado de si mesmo pauta um modelo de filosofia que está em construção e que pede um esforço diário de 
autoconhecimento e transformação que é pessoal e intransferível e se efetiva mediante um exercício constante.

\section{FiLOSOFAR, UM EXERCÍCIO ESPIRITUAL ENQUANTO PRÁTICA ÉTICA}

O cultivo da alma, isto é, o cuidado de si para ser mais livre, mais justo, mais uno, mais sensato, mais feliz, se realiza mediante um exercício. Justificaremos isso na esteira das contribuiçóes filosóficas de Michel Foucault e Pierre Hadot, os quais concebem a filosofia como um modo de vida. Concomitante a isso, mostraremos que o exercício filosófico ou espiritual é uma prática eminentemente ética.

A concepção hadotiana de filosofia, enquanto modo de vida desenvolvido na Grécia Antiga, se desenvolve através da noção de exercício espiritual. Os filósofos da Antiguidade

[...] são considerados filósofos não porque desenvolvem determinados discursos filosóficos, mas pelo fato de viver filosoficamente. O discurso integrou-se em sua vida filosófica [...]. Para estes, a própria filosofia é entendida, antes, como uma forma de vida e não como um discurso. (HADOT, 2006, p. 13).

O conceito de exercício espiritual, amplamente utilizado pelo

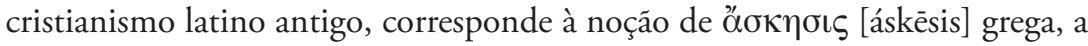
qual não se reduz à dimensão do ascetismo, mas é uma prática, um exercício da alma que não se restringe ao aspecto racional.

O uso do termo espiritual - que, inicialmente, pode causar certa estranheza aos leitores - é justificado pela imprecisão e inadequação do uso de outros termos mais restritivos. De fato, "[...] é necessário, porém, usar este termo, porque nenhum dos outros adjetivos que podemos usar 'físico', 'moral', 'ético', 'intelectual', 'do pensamento', 'da alma' - cobre todos os aspectos da realidade que nós queremos descrever" (HADOT, 1995, p. 81); isto é, o termo espiritual engloba muito mais o aspecto de olhar para si mesmo, encerrando, assim, a proposta do conhecimento de si tão marcada pelo estilo filosófico socrático e das escolas neoplatônicas - estoicismo, cinismo, epicurismo.

Mesmo que a tradição dos exercícios espirituais preceda Sócrates, foi este quem fez emergir tal tema, no ocidente, chamando a todos a um despertar da 
consciência moral, através do diálogo. O cuidado de si se dá mediante o processo de autoconhecimento, de compreensão de si. Não se trata táo somente de um conhecimento e da formação da identidade própria, mas de uma concepção de ser filósofo, de maneira que o saber diz respeito ao modo de conduzir sua vida. O conhecimento de si mesmo impóe um reconhecimento como náo sábio, como alguém a caminho da sabedoria, além de uma compreensão da essência de ser, do verdadeiro eu, por meio de um exame de consciência que aponte o que nos constitui separadamente do si mesmo que nos constitui.

Já mencionamos que a missão socrática pode ser resumida na preocupação de persuadir os atenienses a serem melhores e mais sensatos, mediante cuidado de sua alma. Nesse sentido, ser filósofo consiste em ater-se ao que é essencial para a consecuçáo dessa meta e compreender-se a partir dos próprios limites - sejam eles de ordem intelectual, espiritual, física etc. da finitude, o que justifica o filosofar como um exercício de aprender a morrer, como lemos no Fédon.

O personagem Musashi expóe diretamente sua preocupação em examinar sua consciência e se avaliar enquanto ser humano. Musashi considerava-se um andarilho na busca da resposta para sua pergunta: que fazer para me tornar uma pessoa melhor? (YOSHIKAWA, 2003b, p. 1358). A pergunta é um pressuposto para que se dedique ao zazen, isto é, o modo de meditação sentado que permite que se concentre e absorva as coisas com a mente tranquilizada e concentrada simplesmente pelo fato de estar imóvel é o que o budismo explica como mobilidade imóvel, pois a progressão espiritual ocorre a partir do início da concentração de si mesmo, da prática meditativa que faz a alma se moldar à sabedoria, esforçar-se sem esforço.

A consciência e a criticidade filosófica de Musashi, ao final da história, evidenciam o quanto caminhara desde o início, pois mostra alguém reflexivo, que náo age meramente pelo instinto e pela efetivação de sua vontade, pela demonstração de sua força. Enquanto desenvolve sua técnica, a partir de sua experiência, percebe que "antes de pensar em governar o mundo, tenho de aprender do mundo" (YOSHIKAWA, 2003b, p. 1530) —, o que corresponde ao que Sócrates conclui, no Alcibiades I, que é necessário buscar ocupar-se de si mesmo para, posteriormente, ocupar-se dos outros. Musashi volta às montanhas — tal como o Zaratustra nietzschiano —, uma vez que percebera que o distanciamento da sociedade, o maior contato com a natureza e a simplicidade de uma vida frugal o auxiliavam no processo de enriquecimento espiritual. 
A filosofia compreendida como um conjunto de exercícios espirituais — tanto representados por $\mu \varepsilon \lambda \varepsilon \dot{\tau} \tau \eta$ [melétē] quanto por ő $\sigma \kappa \eta \sigma \iota \varsigma$ [áskēsis], que significam meditaçãolexercício e exercíciolginástica - implica a conversão

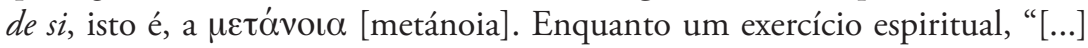
a filosofia, então, não se mostra originalmente como uma elaboração teórica, mas como método de formação de uma nova maneira de viver e perceber o mundo, como uma tentativa de transformação do homem." (HADOT, 2006, p. 56). Trata-se, pois, de um tipo de paideia, de formação do homem que não se baseia única e exclusivamente no conhecimento técnico e na construçáo conceitual por dizer respeito ao modo de se portar e se dispor na vida privada e pública, ao repensar e realinhar seu ser-no-mundo [In-der-Welt-sein].

A filosofia tem, desde seu princípio, um papel de revolução no modo de viver em comunidade e de ruptura com quem não leva uma vida de modo filosófico (HADOT, 2006, p. 214). O ponto é que não há forma de tornar-se filósofo, em seu exercício conceitual, sem que isso altere, mesmo que em pequena escala, seu modo de viver. A plenitude filosófica passa pelo exercício de olhar para si mesmo, aplicar-se e cultivar-se enquanto sujeito que compreende a si mesmo e ao mundo. As propostas da filosofia antiga e da contemporânea são claramente distintas, na medida em que "[...] a filosofia antiga propóe ao homem uma arte de viver, ao contrário da moderna, que advoga, em primeiro lugar, pela construção de uma linguagem técnica reservada a especialistas." (HADOT, 2006, p. 246). Por conseguinte, uma lição da filosofia antiga consiste em "[...] convidar o homem a transformar-se a si mesmo. A filosofia implica conversão, transformação do modo de ser e de viver, busca da sabedoria." (HADOT, 2006, p. 249).

Musashi converte-se, ao experienciar a clausura e render-se à busca da sabedoria, pois, ao se considerar um bushi - guerreiro - , percebe que deve ponderar sobre suas atitudes, pensar antes de deliberar e agir sob um código de honra ou de conduta muito forte. Nesse sentido, ao se colocar como um rounin - um samurai andarilho que não serve a nenhum senhor feudal - restabelece-se enquanto ser humano, reposicionando-se e modificando completamente seu modo de vida. Dessa maneira, trata-se de uma postura similar à adotada pela filosofia antiga, a qual exigia que seus discípulos ponderassem sobre sua atitude diante do mundo e transformassem suas vidas, por meio do que aprendiam na escol[h]a filosófica.

A técnica desenvolvida por Musashi é concebida como uma dança própria para manter diversos inimigos à distância —, e, por meio de práticas 
meditativas, percebe o todo, sente-se parte da natureza, capaz de interpretar sinais provenientes da realidade que o circunda. Mas sua técnica não era proveniente especialmente de livros, uma vez que sua busca por sabedoria, seu exercício de consciência de limite e de sua própria finitude, não advinha de um discurso filosófico, propriamente dito, senão que da própria vida, da existência e da análise desta, visto que

Musashi era ainda um principiante, não tivera tempo para tecer teorias sobre estilos e formas até então. Em parte por obra do destino, ele tinha percorrido sem vacilar um único caminho: o da prática. Seu conhecimento advinha da prática. Teorizava posteriormente, em seus momentos de repouso. (YOSHIKAWA, 2003a, p. 919).

O aprendizado, pois, advinha da prática, de suas vivências, de suas experiências, as quais se tornavam parte de sua técnica, sua teoria, seus escritos.

Parte do sentido dos exercícios de ordem espiritual, na prática filosófica, encerra-se na consciência de pertencimento a uma realidade, a um mundo e a um conjunto de indivíduos que vivem em um mesmo plano. A consciência do Todo é um aspecto necessário para o filósofo, que analisa e interpreta as coisas do ponto de vista holístico, com capacidade de compreender o Todo, e não somente suas partes desintegradas. Dessa forma, é possível se inteirar como parte de uma realidade maior e da possibilidade de expansão de si, em diferentes níveis, de sorte que "[o] eu terá, assim, um duplo sentimento, o de sua pequenez, ao ver sua individualidade corporal perdida no infinito do espaço e do tempo, e o de sua grandeza, ao experimentar seu poder de abarcar a totalidade das coisas.” (HADOT, 1998, p. 225). O exercício espiritual, como vemos em Sócrates e Musashi, não é de ordem puramente pessoal e subjetiva, mas diz respeito à compreensão, situação do todo e a uma prática ético-política.

As obras filosóficas da Antiguidade foram escritas em determinado contexto de vida filosófica, e devemos compreendê-las dessa forma, porque a intenção não era apenas desenvolver um discurso teórico com finalidade em si mesmo, mas um discurso que influenciasse o comportamento, o modo de ser de quem o lê. Trata-se, pois, de uma perspectiva formativa, além de informativa, de desenvolvimento de um habitus, o qual pressupóe mudança no modo de [vi]ver [n]o mundo. A vida filosófica é uma vida que se distancia da vida prosaica e ordinária, já que "[...] ser um filósofo implica uma ruptura com o que os céticos chamavam ßíos, isto é, a vida diária [...]” (HADOT, 
1995, p. 56). A função do discurso filosófico, nesse sentido, é tornar o filósofo, que se encontra a caminho da sabedoria, consciente das condiçóes e dos riscos assumidos, ao optar por uma vida filosófica, que se dá através de exercício espiritual constante, ou seja, de uma orientação amistosa e dialógica: "A verdadeira educação é sempre oral, porque somente a palavra falada torna o diálogo possível, isto é, torna possível para o discípulo descobrir a verdade por si mesmo entre o jogo de perguntas e respostas e também para o mestre adaptar seu ensino às necessidades do discípulo.” (HADOT, 1995, p. 62).

Os "exercícios espirituais são necessários para a cura da alma" (HADOT, 1995 , p. 87), de sorte que, se não estamos buscando a filosofia com objetivo de conhecermo-nos a nós mesmos e, dentro do processo de autoconhecimento, de cultivar a nós mesmos, estamos perdendo uma cor tônica do espectro de cores filosófico. $\mathrm{Na}$ caminhada filosófica, na escolha por um modo de ser e viver filosófico, "[o] que conta não é a solução de um problema particular, mas a estrada percorrida para alcançá-lo.” (HADOT, 1995, p. 92). Enquanto exercício espiritual, a importância da filosofia reside no seu próprio processo, em seu acontecer, de acordo com o que lemos da proposta socrática: "[...] a filosofia era um modo de existir-no-mundo, que deveria ser praticado a cada instante, e cujo objetivo era transformar o todo da vida do indivíduo." (HADOT, 1995, p. 265). Essa prática do cuidado de si enquanto exercício espiritual constante, como se vê, é eminentemente ética e, consequentemente, política, como veremos a seguir.

\section{Cuidado de Si MESMo E EXERCÍCIO ESPIRITUAL ENQUANTO PRÁTICA ÉTICO- POLÍTICA}

Portanto, digo, não haverá cessação dos males às classes da humanidade até que a classe dos que são filósofos verdadeiros e autênticos alcancem a supremacia política, ou então a classe dos que detêm o poder nos Estados tornem-se, por alguma providência divina, autenticamente filosóficos. (PLATÃO, Carta Sétima, 326 a - 326 b).

Após termos tratado da perspectiva da filosofia como prática do cuidado de si, mediante exercício espiritual enquanto atividade ética, nas trilhas do Sócrates da Apologia e da trajetória de Musashi, mostraremos, a seguir, que ambos visam - como nos aponta exemplarmente Sócrates, no Alcibiades $I$ - a que essa proposta tem um escopo político. O exercício do cuidado de 
si mesmo pressupóe e implica uma preparação para o exercício do cuidado e governo de outros. A missão socrática consistia, como vimos, em persuadir atenienses a serem melhores, mais sensatos pelo cultivo da sabedoria. Dessa forma, quem pratica a filosofia, dentro dos parâmetros que aqui sustentamos — emblematicamente representados nas figuras de Sócrates e Musashi —, tem por escopo último a reconstrução da sociedade, da política na qual está inserido.

Em última instância, ser filósofo implica o compromisso ético e político, que é performático e transformador, conforme advertência e lição de Sócrates (Alcibiades, 132 b) para Alcibíades: "Exercita-te primeiro [ $\gamma u ́ u v \alpha \sigma \alpha$ $\pi \rho \tilde{\omega} \tau o v=$ gýmnasai prốton], caro amigo, e aprende o que é preciso conhecer antes de entrares à política. Deves esperar até ter aprendido, a fim de que estejas armado com o antídoto [ả $\alpha \varepsilon \xi ı \varphi \alpha ́ \alpha \mu \alpha \kappa \alpha=$ alexiphármaka] e, assim, não sofra danos." A epígrafe da presente seção versa sobre a possibilidade de acabarmos com os males/sofrimentos, por meio de um governo justo regido pela prática da sabedoria, conforme a Carta Sétima de Platão.

O processo de compreensão de si de Sócrates e Musashi é eminentemente ético, pois o movimento de conhecimento de si e de cuidado de si pressupóe uma transformação no modo de ser no mundo, além de servir como orientação no mundo. Ora, trata-se da orientaçấo, do modo de ser e de se[com]portar no

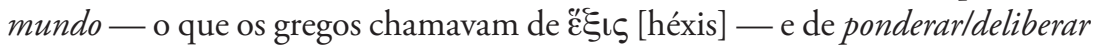
sobre a melhor ação.

A interiorização e os exercícios espirituais adquiridos ao longo da caminhada de Musashi tornam-se decisivos para a concepçáo de que seja possível utilizar o caminho da espada como forma de moralização e valorização da própria existência, de sorte que pode ser usada como forma de governo dos outros, porque Musashi percebe que, além de ser um meio para vencer $o$ próximo, o caminho da espada - assim como a filosofia compreendida como prática de si, como ascese espiritual - é um meio para vencer a si próprio e alcançar a vitória na vida (YOSHIKAWA, 2003b, p. 1177). A conscientização de Musashi se dá de forma poética, ao afirmar:

A enxada é também uma espada, /Assim como / A espada é também uma enxada, / Na lavoura não se esqueçam da rebeliâo, / Mas rebelados, não se esqueçam da lavoura, / Dispersos, voltem sempre a unir-se. / E lembrem-se ainda: / Os caminhos do mundo não podem ser contrariados. (YOSHIKAWA, 2003b, p. 1207). 
Quando exorta os camponeses que lutem por suas vidas, que se unam, que fiquem alertas às injustiças, para que não sejam subjugados, está edificandoos para que ascendam à autonomia de suas razóes e escolhas. Dessa maneira, Musashi chega à conclusão de que sua arte poderia ter um fim político:

\begin{abstract}
"Se a esgrima é realmente um caminho, deve haver um modo de empregar a moralidade inerente a esse caminho para valorizar a vida", pensou. "Vou usar a esgrima não só para a evolução pessoal, mas também como meio para governar um povo e administrar um país”, concluíra. (YOSHIKAWA, 2003b, p. 1117).
\end{abstract}

Se Díon tivesse conseguido incutir na mente do governante de Siracusa os preceitos filosóficos de Platáo, certamente Siracusa seria diferente do que se apresentara diante de Platão, em suas visitas, e a vida de Díon teria sido poupada. Seguindo o caminho filosófico proposto por Platáo (Carta Sétima, 332 e), Dionísio II teria se tornado mais racionallinteligente e prudenteltemperante

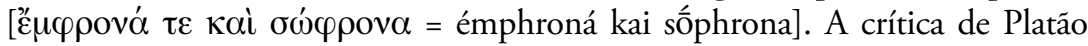
é similar à crítica que Musashi recebe do polidor de espadas, isto é, de que um espadachim sem caminho, desregrado, sem princípios, é como uma lâmina cega; há potência, mas não há efetividade naquilo para que foi feita. Em linguagem platônica, poderíamos nos referir ao que o filósofo afirma acerca de Dionísio II, que, se tivesse personificado filosofia e poder [ philosophía te kai dýnamis] (Carta Sétima, 335 d), teria se consagrado como um bom governante, e não um tirano, pois teria os preceitos filosóficos de como governar a si mesmo como ponto de partida para governar os outros.

Em diálogo com o polidor de almas, Musashi reconhece que sua tese de caminho da espada para governar um pais tinha fundamento, quando este assevera que as espadas estavam decaindo de qualidade, de geração em geração. Essa decadência indicava tanto uma perda da arte de forjaria/cutelaria, mas, também, no manejo, no cuidado e na utilização destas com o princípio de lembrar o guerreiro de sua ligação sagrada com seus votos de honra, com o posicionamento de retidáo da vida. A espada japonesa, pois,

[...] foi idealizada como instrumento para pacificar o império, protegê-lo do mal e dele expulsar os demônios. Ao mesmo tempo, a espada destina-se aprimorar o caminho dos homens, e deve ser levada à cintura dos que estáo no comando como contínua advertência no sentido de manter a própria compostura e de vigiar a si mesmos para não incorrer em erros. Ela é a alma do samurai, e o seu polidor tem de realizar o trabalho sem perder de vista tais princípios. (YOSHIKAWA, 2003b, p. 1236-1237). 
Portanto, não se trata apenas de discurso, de conhecimento, de ciência, senão que de utilizar esse conhecimento em prol de algo melhor, praticar a justiça e não apenas buscar saber o que é justiça. "O líder, a pessoa que comanda, o soberano, deve, realmente, ser mestre de si mesmo, no sentido de que ele deve ser temperante, capaz de manter seus desejos dentro de limites apropriados, moderá-los, evitando a discórdia, que previne a sinfonia" (FOUCAULT, 2006, p. 270); ou seja, não basta ter intenção de comandar, de dirigir um determinado grupo de pessoas, caso não haja capacidade de autocontrole, de domínio de si mesmo e de cultivo da própria alma. O filósofo tem a tarefa de dizer a verdade e alertar aqueles desatentos, que não se interessam pela filosofia e/ou por sua vida regrada e cheia de escolhas que reduzem algumas variáveis do que o espírito humano pode desejar.

Díon teria tirado Siracusa do sistema tirânico e da escravidão, através da aplicação das melhores e mais convenientes leis, caso fosse governada

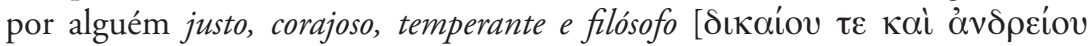

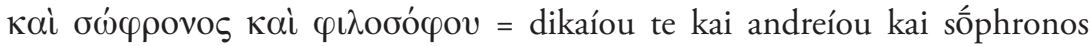

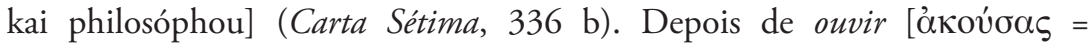
akoúsas] a verdadeira doutrina filosófica, que se baseia também no cuidado de si e nos exercícios espirituais descritos nas seçóes anteriores, se o pupilo for verdadeiramente filósofo, em harmonia com o tema e digno deste, por ser

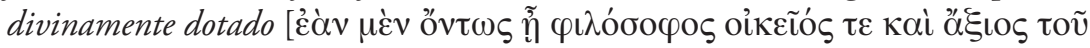

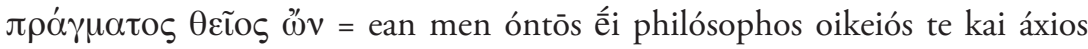

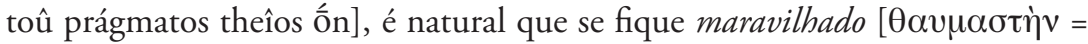

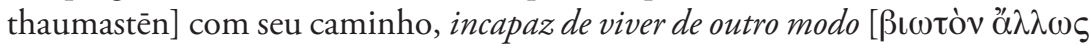

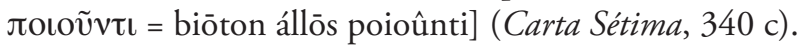

Esse é o sentido último da perspectiva ético-política da filosofia, a saber, que tal estado de espírito, esse modo de ser filosófico, esteja presente também nos momentos mais simples e prosaicos da vida humana. Tais ensinamentos, como mostram Sócrates, Platáo e Musashi, não são esquecidos, e não é possível deixar de ser filósofo momentaneamente, ao longo da vida, pois se trata de uma transformação existencial que deixa marcada a vida inteira. Quem acha que viver filosoficamente é difícil e não muda seu modo de ser, a partir do exercício filosófico, não é um autêntico filósofo, pois "[e]stes que, na verdade,

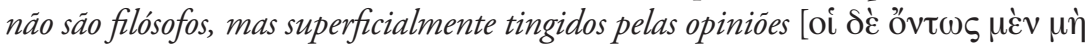

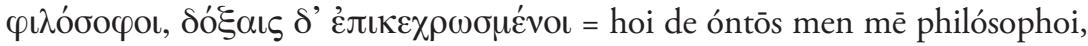
dóxais d'epikechrōsménoi] (Carta Sétima, 340 d), acham que o exercício filosófico e tudo que tal vida exige é muito complicado, acabam por desistir. 
Grande parte do ensinamento filosófico se dá por meio do convívio com o outro e na perspectiva de um discípulo que aprende, a partir da vida em comum - que poderíamos traduzir como amizade comprometida do diálogo e da prática dos exercícios espirituais. Assim como ressaltamos nas seções anteriores, Musashi só se converte existencialmente, quando enclausurado na torre, provido de ócio para refletir sobre sua prática de vida com relação às teorias com que faz contato, através da leitura e do exercício meditativo. Além disso, sua caminhada filosófica só foi possível pelo incentivo de Takuan, o monge que o coloca na esteira do cuidado de si e abre os olhos de Musashi para lhe despertar uma vida mais autêntica e harmoniosa, a qual se institui por meio de um insight, e não por insistência e/ou simples leitura de Musashi. Isso significa que, ao comprometer-se no exercício meditativo, no pensar profundamente sobre sua própria vida, em uma espécie de exame da consciência, também de conhecimento de si, instaura-se uma experiência filosófica, que não se reduz a um conhecimento a ser aplicado, pois demanda uma reação de hábito, de modo de ser, de mudança de vida.

A filosofia não se encerra no mesmo âmbito dos outros tipos de saberes,

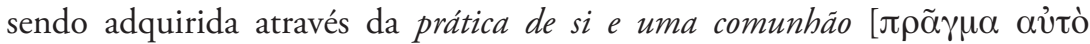

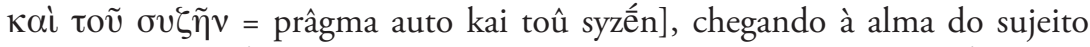

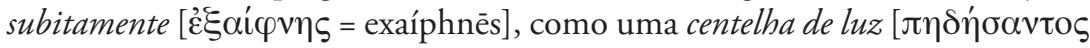
¿̇ $\xi \alpha \varphi \theta \dot{\varepsilon} v \varphi \tilde{\omega} \varsigma$ = pēdếsantos exaphthen phốs] (Carta Sétima, $341 \mathrm{c}-\mathrm{d})$. Tratase, portanto, de uma prática reflexivo-meditativa que, para a melhor realização de si mesmo e da compreensão de sua realidade, da história na qual se está inserido etc., orientando quem busca a filosofia a um modo de vida mais virtuoso e capaz de mudar outras vidas.

Dito isso, vemos que a advertência socrática nos diz respeito, se quisermos filosofar hoje: "[...] não estás envergonhado em cuidares da aquisição de riqueza e reputação, quando não cuidas nem pensas sobre a sabedoria, a verdade e o aperfeiçoamento da alma?" (Apologia, 29 e). Ou seja, em sua admoestação, no Alcibiades I (134b), ressalta que "[...] não é aquele

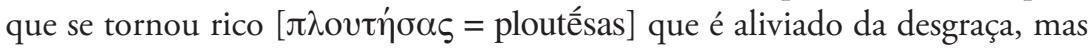

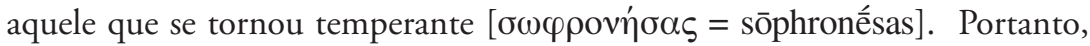
não são muros, trirremos ou arsenais que as cidades precisam, Alcibíades, nem

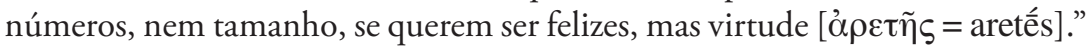
A efetivação de uma vida mais livre, mais justa e mais feliz passa pelo exercício constante do cuidado de si mesmo enquanto uma prática ético-política. 


\section{CONSIDERAÇÓES FINAIS}

Nossas reflexóes nasceram da provocaçáo da pergunta socrática "O que é cuidar de si mesmo?" e tiveram por escopo, aqui, justificar que o filosofar, enquanto constante cuidado de si mesmo, se faz mediante um exercício de natureza espiritual. Argumentamos que esse exercício, à luz da postura de Sócrates e de Musashi, instituem práticas ético-políticas exemplares para a atividade filosófica.

Sustentamos nossa hipótese, salientando que o filosofar se erige sobre o cultivo e cuidado de si. A atividade filosófica é tecida pela construção conceitual que afeta a vida de quem se envereda por essa direção, como acompanhamos nos passos de Sócrates e de Musashi. Filosofar, visto assim, implica e possibilita uma conversão de si, uma reorientação existencial em relação a si mesmo e ao nosso lugar no mundo. A vida torna-se náo apenas o ponto de partida, no que tange à prática filosófica, mas o destino final, na medida em que nos compreendemos como filósofos, à busca de um discurso verdadeiro e da harmonização da vida como uma existência digna e autêntica de ser vivida.

Ora, o cuidado de si efetiva-se mediante um exercício espiritual que é sempre autoimplicativo. A busca e a realizaçáo da nossa felicidade ou harmonia final passa pela autocompreensão e explicitação do nosso lugar no mundo. Esse percurso é perceptível na figura de Musashi, um exemplo literário do processo filosófico socrático-platônico, no qual conhecimento e cuidado de si estão entrelaçados. Ressaltamos que a filosofia, desde seus primórdios, englobava o aspecto de guia existencial, de interiorização do discurso filosófico, como uma escolha de vida filosófica, de caminho à sabedoria, de uma vida virtuosa ou ética.

Ao final da nossa reflexão, mostramos que a dimensão prática e ética das práticas de si, destacando os modos de vida filosóficos de Sócrates e Musashi, pressupóe e se plenifica no exercício político, pois visa não apenas a um esclarecimento e um despertar pessoal e individual, porém, a uma volta à caverna, isto é, um resgate daqueles que ainda não foram iniciados pelo processo filosófico. Ao retomar a Carta Sétima de Platão, justificamos como a proposta filosófica mal orientada — personificada em Dionísio II — se torna abominável e prejudicial náo só ao sujeito, mas à comunidade na qual este se insere. Esclarecemos, também, que Musashi buscava, com o caminho da espada, uma mudança espiritual para si mesmo, mas que também se refletia em sua tentativa de melhorar a realidade da vida de seus conterrâneos como um fim último de sua caminhada filosófica. Dessa forma, o caminho da espada 
o incentivava a ter retidáo de espírito, ser justo, corajoso e aberto à alteridade, uma vez que a efetivação de sua autorrealização também se desdobrava em um desenvolvimento ético-político.

O esforço para compreender princípios como a liberdade, o bem, a justiça configura a experiência hermenêutica que implica a aquisiçáo de uma visão mais completa sobre o real. Esse exercício compreensivo já é, em si mesmo, ético, porque seu escopo não é exterior ao filósofo, mas lhe diz respeito. Compreendendo a filosofia como algo que contribui para nos tornarmos melhores, a história do personagem Musashi mostra que sua busca sincera para ser melhor, utilizando o código de ética dos samurais e os preceitos do zen-budismo, tornou-o melhor e capaz de apreciação estética como um filósofo em busca de autoconhecimento, de constante ascese meditativa e vida desapegada à materialidade - exatamente o que representa um Sócrates em nossa cultura ocidental e que tipifica a figura do filósofo ideal, o qual dialoga e forma discípulos através de suas próprias atitudes, exemplificando através de seu próprio comportamento.

O exercício de compreensão dos princípios afeta a vida daquele que se envereda por esse caminho, de sorte que ele institui, à sua luz, uma prática enquanto trabalho teórico. $\mathrm{O}$ movimento dialético de compreensão se completa com a aplicaçáo do saber — o que não significa posteridade temporal —, pois a experiência já é ético-política, isto é, não há, primeiro, a construção teórica e depois uma ética. Por fim, responder, hoje, à pergunta o que é cuidar de si? significa um exercício de autocompreensão, que, por sua natureza, é ético-político nas pegadas de Sócrates e de Musashi.

ROHDEN, Luiz; KUSSLER, Leonardo Marques. Philosophizing as care of the self: an ethical-political spiritual exercise. Tans/form/ação, Marília, v. 40, n. 3, p.93-112, Jul./Set., 2017.

\footnotetext{
Abstract: The text we present here is an answer to Plato's provoking question "What is it to care for oneself?" The answers we provide are aspects of our proposal for understanding philosophy as something that is realized as a spiritual exercise; this understanding, for its part, supports the hypothesis of philosophy as a way of life. Starting with Greek philosophy we will make explicit the exercise of the cultivation of the self embodied in Socrates; then, turning to Eastern philosophy, we shall examine the character of Musashi. Both personify the option for a style of philosophical life and way of being - the first through paths of dialogue, the second through experience - and highlight the necessity of the spiritual evolution of the soul by means of a contemplative life. Consequently, in addition to exploring the great proximity between the Greek and the Eastern philosophical traditions, we will find common ground between them in thought as ethical exercise.
} 
Keywords: Plato. Care of the self. Spiritual exercise. Ethical-political exercise. Philosophy as a way of life.

\section{REFERÊNCIAS}

ARISTOTLE. Aristotle in 23 Volumes - v.17, 18. Translated by Hugh Tredennick. Cambridge: Harvard University Press; London: William Heinemann, 1989.

DANTO, A. C. A transfiguração do lugar-comum: uma filosofia da arte. São Paulo: Cosac Naify, 2010.

FOUCAULT, M. História da sexualidade 3: o cuidado de si. Tradução de Maria Thereza da Costa Albuquerque. 8. ed. Rio de Janeiro: Graal, 2005.

- A hermenêutica do sujeito. Tradução de Márcio Alves da Fonseca e Salma Tannus Muchail. São Paulo: Martins Fontes, 2006.

The government of self and others: lectures at the Collège de France, 1982-1983.

Translated by Graham Burchell; English Series Editor: Arnold I. Davidson. Basingstoke: Palgrave Macmillan, 2010.

. The Government of self and others II (The Courage of the Truth): lectures at the Collège de France, 1983-1984. Translated by Graham Burchell; English Series Editor: Anrnold I. Davidson. Basingstoke: Palgrave Macmillan, 2011.

GADAMER, H.-G. Hermeneutik: theorie und praxis (1996). In:

Hermeneutische Entwürfe: Vorträge und Aufsätze. Tübingen: Mohr Siebeck, 2000a.p. $3-12$.

- Da palavra ao conceito: a tarefa da hermenêutica enquanto filosofia. In: ALMEIDA, C. L.; FLICKINGER, H.-G.; ROHDEN, L. Hermenêutica filosófica: nas trilhas de Hans-Georg Gadamer. Porto Alegre: EDIPUCRS, 2000b. p. 13-27.

HADOT, P. Philosophy as a way of life: spiritual exercises from Socrates to Foucault. Edited with an introduction by Arnold I. Davidson. Translated by Michael Chase. Oxford; Cambridge: Blackwell, 1995.

- ¿Qué es la filosofía antigua? Traducción de Eliane Cazenave Tapie Isoard. México: Fondo de Cultura Económica, 1998.

. Ejercicios espirituales y filosofía antigua. Prefacio de Arnold I. Davidson.

Traducción de Javier Palacio. Madrid: Ediciones Siruela, 2006. (Biblioteca de Ensayo 50; Serie Mayor).

MUSASHI, M. The book of five rings. Translated from the Japanese by Thomas Clearly. Including The book of family traditions on the Art of War, by Yagiu Munenori. Boston; London: Shambhala, 1993.

PLATO. Platonis opera, v. I - Euthyphro, Apologia Socratis, Crito, Phaedo, Cratylus, Theaethetus, Sophistica, Politicus. Ed. by John Burnet. Oxford: Oxford University Press, 1905. 
. Platonis opera, v. II - Parmenides, Philebus, Symposium, Phaedrus, Alcibiades I, Alcibiades II, Hipparchus, Amatores. Greek texts ed. by John Burnet. Oxford: Oxford University Press, 1910. (In 5 volumes).

. Platonis opera, v. V - Minos, Leges, Epinomis, Epistulae, Nothegomenoi. Greek texts ed. by John Burnet. Oxford: Oxford University Press, 1913. (In 5 volumes).

Plato in twelve volumes, v. 1 - Euthyphro, Apology, Crito, Phaedo. Translated by Harold North Fowler; Introduction by W. R. M. Lamb. Cambridge: Harvard University Press; London: William Heinemann, 1966.

. Plato in twelve volumes, v. 7 - Letters. Translated by R.G. Bury. Cambridge: Harvard University Press; London: William Heinemann, 1966.

. Plato in twelve volumes, v. 8 - Alcibiades 1, Alcibiades 2, Hipparchus, Lovers, Theages, Charmides, Laches, Lysis. Translated by W. R. M. Lamb. Cambridge: Harvard University Press; London: William Heinemann, 1955.

RICOEUR, P. La vida: un relato en busca de narrador. Ágora, v. 25, n. 2, p. 9-22, 2006.

ROHDEN, L. Entre filosofia e literatura: exercício de transfigurar a morte para viver. In: - (Org.). Entre filosofia e literatura: recados do dito e náo dito. Belo Horizonte: Relicário, 2015a. p. 41-62.

. Transfiguração do olhar pela filosofia e literatura: entre Sócrates e Miguilim. In: SOUZA, D. G.; LIMA, F. J. G. Filosofia e interdisciplinaridade: festscrift em homenagem a Argemir Bavaresco. Porto Alegre: Fi, 2015b. V. 26. p. 580-606.

ROHDEN, L.; KUSSLER, L. M. Dialética, experiência e intuição: entre hermenêutica filosófica e filosofia budista. Kriterion, Belo Horizonte, v. LVII, n. 133, p. 261-282, jan./ abr. 2016.

SŌHŌ, T. A mente liberta: escritos de um Mestre Zen a um Mestre da Espada. Tradução de Marcelo Brandão Cipolla. São Paulo: Cultrix, 1986.

TANABE, H. Philosophy as metanoetics. Translated by Takeuchi Yoshinori, with Valdo Viglielmo and James W. Heisig. Foreword by James W. Heisig. Berkeley: University California Press, 1986.

YOSHIKAWA, E. Musashi. Tradução e notas de Leiko Gotoda. Prefácio de Edwin O. Reischauer. 9. ed. São Paulo: Estação Liberdade, 2003a.V. 1.

- Musashi. Tradução e notas de Leiko Gotoda. 6. ed. São Paulo: Estação Liberdade, 2003b. V. 2.

Recebido em 14/12/2015

Aceito em 20/10/2016 